Article

\title{
Evaluation of a Disposable-Diaper Collection Trial in Korea through Comparison with an Absorbent-Hygiene-Product Collection Trial in Scotland
}

\author{
Kyung-Shin Kim ${ }^{1}$ and Kyoung Jin Kim ${ }^{2, *}$ \\ 1 Department of Environment \& Energy Engineering, Sungshin University, Seoul 01133, Korea; \\ kyskim@sungshin.ac.kr \\ 2 Department of Early Childhood Education, Wheelock College, Boston, MA 02215, USA \\ * Correspondence: kkim@wheelock.edu; Tel.: +82-617-879-1361
}

Received: 4 January 2018; Accepted: 9 March 2018; Published: 11 March 2018

\begin{abstract}
This study was designed to analyze the feasibility of economic aspects assuming that the policy of diaper recycling is necessary. With respect to economic feasibility, the collection and transportation of the diaper waste, which accounts for much of the cost, need to be optimized. Starting with the results of a collection trial in Scotland (2012), the method used in a collection trial in Korea (2014) was analyzed to identify problems incurring additional costs. This paper targeted daycare centers in Nowon-Gu, Seoul-because of the quantity of waste diapers they produce and the efficiency of collection - to identify the problems and to predict the cost of collection. This study evaluated multiple scenarios in light of their collection costs, discovering factors that could improve the system and reduce the cost and created the most economically feasible and optimized collection model. This paper will serve as empirical evidence proving the economics of diaper collection when the regulation is revised or amended in the future.
\end{abstract}

Keywords: diaper recycling; collection trial; economic feasibility; collection and transportation costs

\section{Introduction}

More than 380,000 tons of waste are produced on a daily basis in Korean municipalities. Solid waste generation has increased in certain areas as a result of changes in consumption patterns and the life cycles of consumer products, some initiated by recycling efforts. Research indicates that over $90 \%$ of parents use disposable diapers since they are comfortable, hygienic, cost-effective and convenient (2017) [1]. According to a life-cycle assessment of disposable diapers for babies and toddlers aged between 0 and two years, 5.87 diapers are used per child every day, which are sent to landfills or incinerators [1-3]. Out of the 240,000 tons of used diapers generated each year in Korea, 141,000 tons $(58 \%)$ are produced at daycare centers [2,4]. The percentage contribution of diapers to the overall weight of trash in general grew gradually to $2.1 \%$ in 2002 and is expected to reach $3.6 \%$ in $2020[1,3,5]$.

Most diapers are basically composite materials that contain plastics (such as polyethylene, polypropylene, etc.), cellulose fibers and super-absorbent particles, all of which are valuable resources $[1,4]$. However, all of them are incinerated or sent to landfills since they are targets for waste charges. According to the Act on the Promotion of Saving and Recycling of Resources (1993), in order to restrict the generation of waste and to prevent the waste of resources, the Minister of Environment imposed fees and collected expenses incurred from the treatment of discarded goods, materials and containers [1,4]. Disposable diapers are one of the items subject to waste charges since they are likely to cause problems in the management of waste $[1,6,7]$. Currently, diaper waste is collected in waste bags and transported to the nearest resource-recovery facilities, where it is buried or incinerated 
without going through the process of separation [4]. Diaper waste is disposed of on a daily basis and its environmental impacts include land use, methane production and the leaching of organic compounds into the soil and groundwater [8-11]. In 2011, Deloitte conducted a study comparing the environmental performance of Knowaste's Absorbent Hygiene Products (hereafter, AHP) recycling process to the standard UK disposal practice-namely, controlled landfill or incineration with energy recovery. The AHP process, (1) diverts AHP waste from the standard waste-disposal avenues, and (2) produces materials that can be reused to manufacture other products. Compared to landfill and incineration, AHP's diaper-recycling process generates up to $71 \%$ fewer carbon emissions, based on an annual capacity of 36,000 metric tons of AHP waste; therefore, a recycling plant could save 22,536 metric tons of greenhouse-gas emissions per year [12].

Along with the environmental effects, technology, social acceptance and economic feasibility also need to be taken into account in promoting the recycling of diaper waste. Regarding technology, various methods for the treatment of diapers have been investigated, such as biodegradation by activated sludge and composting, followed by recycling [4]. Composting can be difficult to handle at municipal facilities due to several problems that can be encountered such as workers' health and safety issues [4]. One alternative solution is recycling technology that has already been developed and is in use in many countries such as The Netherlands, the UK and Japan. Knowaste technology is one of the methods, producing 70,000 tons/year in the Netherlands and 36,000 tons/year in the UK. The Knowaste facility has announced closure of its West Bromwich facility in the UK. Currently, the Knowaste site in the UK is no longer operational although the company is seeking an alternative site in the London area. Proctor and Gamble were also investing in diaper recycling technology in Europe and investigating the factors that influence the sustainability of diapers using life cycle assessment. Total Care, a Japanese recycling company, produces 5000 tons/year with its own technology [13-18].

A number of studies on policy acceptance by the public have been conducted in Korea. Mok (2006) surveyed to ascertain perceptions of the acceptability of diaper recycling. The results showed that $73 \%$ of respondents were in full agreement with participating in diaper recycling and $90 \%$ of them would do so if proper collection methods were put in place [4,17,18]. In 2014, the Ministry of Environment researched the methods for diaper recycling. They analyzed collection, recycling cases and policy, then proposed collection and treatment systems. To determine the social acceptance for diaper recycling, a survey was conducted of 400 consumers using diapers. These results showed $75 \%$ of respondents in agreement with diaper recycling and $98 \%$ of them saying they would do so, if proper collection methods were employed. However, $46 \%$ of them were concerned about aspects of the collection process and sanitation matters $[4,18]$.

To achieve economic feasibility in diaper recycling, the collection and transportation of diaper waste - which account for much of the cost-need to be optimized. To that end, we analyzed the results of the Scottish AHP collection trial held in 2012. The analysis included background facts, the method of the collection trial, the selection of participants and the monitoring of the trial. This review was reflected in the design of the disposable-diaper collection trial in Korea. According to research by the Korean Ministry of Environment (2014), diaper collection would be economically feasible with an optimized recycling process. However, it was difficult to secure reliable results since there were not enough data on the costs of collection and transportation, which account for much of the total cost. Therefore, it was necessary to conduct a collection test on diapers to identify unforeseen problems and cost-related factors during the collection. Thus, this study was intended to identify problems with collection and to forecast costs by performing a collection trial on daycare centers with large quantities of diapers. By discovering the factors that would improve the system and reduce the cost, this paper contributes to the economic efficiency of diaper recycling. Further, a more economically efficient diaper recycling system will appear through the monitoring of the diaper-disposal behavior of the participants. In the following section, the basic information regarding the collection trial in Scotland will be presented first; then the collection trial in Korea will be laid out in detail. 


\section{Collection Trial in Scotland}

\subsection{Background}

The Scotland Waste Regulations (2012) will play a key role in assisting Scotland to reach its ambitious target of $70 \%$ recycling by 2025 . Efforts have been made to achieve this $70 \%$ recycling target but one of the remaining types of waste is the commercial absorption product. Scottish councils now want to collect absorption products that are recycled at home. Since April 2012, four councils participated in a six-month trial and various collection methods have been adopted for actual operation and monitoring [19]. This is summarized in the report, "The evaluation of the absorbent hygiene products collection trials in Scotland' (2013).

\subsection{Collection Trial Method}

The collection trial was opt-in, with householders required to contact the council via a contact center to request a collection. The qualification criteria were being in a trial area and the presence of children (or elderly/infirm residents) who required diapers (nappies)/sanitary products. Collection frequency of most participating households was the weekly base. Two types of service were offered: (1) a waste bin (container) provided to participants' curbside and (2) recycling sacks that participants transported to the Households Waste Recycling Center (HWRC). The service types are described in Table 1. Dunfermline (Type 5) and Coatbridge (Type 6) were HWRC-based systems and HWRC schemes needed bigger containers than curbside systems.

Table 1. Service types in the Scottish trial.

\begin{tabular}{|c|c|c|c|c|}
\hline Type & Site & Container & Sacks & Frequency \\
\hline 1 & Stirling & $120 \ell$ bin & No sack & Every week \\
\hline 2 & Crieff & $120 \ell$ bin & $30 \ell$ sack & Every week \\
\hline 3 & Auchterarder & $87 \ell$ bin & $80 \ell$ sack & Every week \\
\hline 4 & Tulloch & No container & $30 \ell, 80 \ell$ sack & Every week \\
\hline 5 & Dunfermline & \multirow{2}{*}{$1100 \ell$ container } & \multirow{2}{*}{$80 \ell$ sack } & \multirow{2}{*}{$\begin{array}{l}\text { Households are responsible for } \\
\text { transporting sacks to the HWRC }\end{array}$} \\
\hline 6 & Coatbridge & & & \\
\hline
\end{tabular}

The householder was registered as participating in a collection trial and a bin or bags were delivered in the next collection round. AHP collections were from the curbside on a weekly basis depending on the trial area and the waste was transferred to the UK's first AHP recycling plant, which was opened recently by Knowaste Limited in West Bromwich and is capable of turning AHPs into recycled products. The average distance from the six cities to West Bromwich was $440 \mathrm{~km}$ (Stirling: 488 km, Crief: 517 km, Auchterarder: 515 km, Tulloch: 172 km, Denfrmline: 503 km, Coatbridge: $450 \mathrm{~km})$.

\subsection{Results}

The results for each trial, using key performance indicators and providing a comparison of their individual performances, are summarized in Table 2. The opt-in rate measured the acceptability of this collection service by the individual AHP-using home. These were calculated by using the actual uptake figures for each trial area compared to the estimated number of households using AHP within each of the trial areas reported from the pre-trial quantitative survey [19]. The weekly tonnage data was based on a compositional survey done in each area. For example, the actual yield was calculated by dividing the average weight of AHP material collected each week in each trial area by the estimated weekly weight of the opted-in household [19]. 
Table 2. Summary of performances by service type in the Scottish trial.

\begin{tabular}{|c|c|c|c|c|c|c|}
\hline & Type 1 & Type 2 & Type 3 & Type 4 & Type 5 & Type 6 \\
\hline Council & Stirling & & Perth and Kinross & & Fife & North Lanarkshire \\
\hline City & Stirling & Crieff & Auchterarder & Tulloch & Denfermline & Coatbridge \\
\hline Opt-in rate & $33 \%$ & $89 \%$ & $57 \%$ & $21 \%$ & $7 \%$ & $6 \%$ \\
\hline Ave. Weekly tons & 0.82 & 0.57 & 0.57 & 0.57 & 0.14 & 0.25 \\
\hline Generation (kg/hh/wk) & 4.82 & 3.34 & 3.34 & 3.34 & 4.56 & 3.02 \\
\hline Actual yield (kg/hh/wk) & 3.63 & 2.88 & 2.88 & 2.88 & 3.88 & 2.59 \\
\hline Collection rate & $75 \%$ & $86 \%$ & $86 \%$ & $86 \%$ & $85 \%$ & $86 \%$ \\
\hline
\end{tabular}

- The opt-in rate by type $(33 \%, 89 \%, 57 \%, 21 \%, 7 \%, 16 \%)$ was the key variable affecting service performance. Curbside performed better than HWRC in terms of opt-in rate, public satisfaction, tonnage collected and cost per ton. Curbside service with a collection container was preferred over the sack-only service (4, Tulloch) in terms of opt-in rate and public satisfaction. Curbside collection service was offered on a weekly basis and sacks were provided with ties. For a successful curbside collection service, households should be provided with a container of sufficient capacity.

- Advertising materials and engagement activities were effective in encouraging the public to opt-in and use the services correctly [19]. Communications to support the introduction of this recycling service included an explanatory leaflet, a postcard reminder of what materials could and could not be recycled using this type of service and direct community-engagement activities to target the relevant groups. Households were motivated to use the AHP curbside recycling services primarily by appeals to the environmental benefits they produce.

A cost summary for the Scottish trial is provided in Table 3 below. The unit cost of type 3 was significantly higher than those for types 1 and 2. The cost of hiring an RCV (Reconnaissance and command vehicle) for service type 1 was significantly higher than the use of Tipmasters for service types 2, 3 and 4 . In Table 2, type 4 (Tulloch) was the sack-only service, so the cost of the container was zero. In fact, each city will share costs by council. Types 2, 3, 4 were located in Perth and Kinross Council and they were all the same area adjacent, so the total costs were the same at $£ 64,208$. The costs for the HWRC were significantly lower than for the curbside method. Dunfermline (Type 5) and Coatbridge (Type 6) used the HWRC based system. In the HWRC system, participants transported recycling sacks to the Households Waste Recycling Center. For each individual household, the transportation costs were incurred but for the local government that implemented the collection trial, there was no transportation cost incurred. For this reason, the cost of collection crew and vehicle was not included in the HWRC system. The cost of the vehicle was just the hire of a collection vehicle and the fuel cost is included in the 'Others' row. The cost of transporting to the Knowaste recycling plant in West Bromwich was included in haulage cost and this haulage cost was included in the 'Others' item in Table 3. Therefore, the haulage cost was higher than would be expected for an AHP service with a recycling plant in Scotland [19].

Table 3. Total costs by service type in the Scottish trial.

\begin{tabular}{ccccccc}
\hline & Type 1 & Type 2 & Type 3 & Type 4 & Type 5 & Type 6 \\
\hline City & Stirling & Crieff & Auchterarder & Tulloch & Denfermline & Coatbridge \\
Container & $£ 11,750$ & $£ 2068$ & $£ 7165$ & 0 & $£ 1066$ & 0 \\
Recycling sack & 0 & & $£ 4656$ & & $£ 213$ & $£ 5094$ \\
Communication & $£ 6488$ & & $£ 2322$ & $£ 5229$ & $£ 6654$ \\
Collection crew & $£ 7762$ & $£ 9510$ & & $£ 7727$ & & \\
Vehicle & $£ 12,638$ & $£ 2591$ & & $£ 2105$ & & $£ 14,338$ \\
Others & $£ 18,754$ & & $£ 21,420$ & $£ 6508$ & $£ 26,896$ \\
Total & $£ 57,392$ & & $£ 64,208$ & & & \\
\hline
\end{tabular}

$£ 1.0=\$ 1.34$.

In order to estimate the cost per ton, the total quantity of diaper waste per household needs to be estimated. In Table 4, households with a child was based on Scotland's Census data. Total waste (ton) 
and diapers $(\mathrm{kg})$ were based on Composition of Municipal Solid Waste in Scotland. Table 2 shows the actual trial result and Table 4 presents forecasted data based on statistical data when calculating the collection cost per ton and assuming possible maximum collection efficiency. The weekly generation $(\mathrm{kg} / \mathrm{hh} / \mathrm{wk})$ in Table 4 was higher than in Table 2 because Table 4 includes ideal statistical data, not actual trial data. Based on the incidence of diaper waste and the number of children between the ages of $0-4$, it is likely that the diaper waste will be between 4.8 and $5.9(\mathrm{~kg} / \mathrm{hh} / \mathrm{wk})$ in each household [19].

Table 4. Diaper waste per household in the Scottish trial.

\begin{tabular}{ccccccc}
\hline & Type 1 & Type 2 & Type 3 & Type 4 & Type 5 & Type 6 \\
\hline City & Stirling & Crieff & Auchterarder & Tulloch & Denfermline & Coatbridge \\
Households with child & 4840 & & 7178 & & 19,187 & 19,299 \\
Total waste (ton) & 24,945 & & 46,903 & & 117,603 & 110,624 \\
Diapers $(\mathrm{kg})$ & 1197 & & 2212 & & 5645 & 5310 \\
Annual generation $(\mathrm{kg} / \mathrm{hh} / \mathrm{yr})$ & 247 & & 308 & & 294 & 275 \\
Weekly generation $(\mathrm{kg} / \mathrm{hh} / \mathrm{wk})$ & 4.8 & & 5.9 & & 5.7 & 5.3 \\
\hline
\end{tabular}

For cost per ton, in the case of Crieff, it was estimated that $£ 26,727$ would be the total cost for a total of $5.9 \mathrm{~kg} / \mathrm{hh} / \mathrm{wk}$ with 200 properties processed in 24 weeks. The cost per ton ranges from $£ 18,000$ at a recovery of $5 \%$ to $£ 939$ at a recovery of $100 \%$ over the period [19]. The actual collection rate of the trial was $75-86 \%$, so the actual collection cost per ton was more than $£ 1100$. It is understandable that the cost of Scottish collection trial was 8 times higher than the cost of other municipal waste. It seemed that this problem has occurred because the amount of diaper alone was not secured and if the collection rate, collection volume and collection system were secured, it will be more economical. In fact, the cost of Korean diaper collection was 10 times higher than the cost of general municipal waste.

\section{Collection Trial in Korea}

Utilizing the most efficient collection tools-the container and recycling sack from the Scottish collection trial- a collection trial was performed in Korean daycares with a large amount of diaper generation. The reasons the daycare centers were selected for the pilot trial were transport convenience and the high diaper-generation rate. Since this collection trial was funded by manufacturers, not by government support, the scope and period of the trial was limited. While the Scottish trial could last for six months thanks to the funding of local governments, the Korean trial ended more quickly due to the smaller amount of funding.

\subsection{Design}

To select a target area for the collection trial, autonomous districts in Seoul were considered where the quantity of diaper waste and the distance of transportation would be optimized. Criteria included: (1) a concentration of apartment housing; (2) at least 300 daycare centers in the district to secure a certain quantity of diapers; and (3) more than 10,000 children enrolled in total at the daycare centers. After consultation with the various municipal administrations, the head of Nowon-Gu showed the strongest interest in recycling resources, which led to its selection as the participating district. A Nowon-Gu official provided information about the daycare centers that could participate in the collection trial. A presentation on the collection trial was held with the support of the daycare association; the directors of the daycare centers were encouraged to apply for the trial and eventually a total of 78 daycare centers confirmed their participation.

\subsection{Method}

Since providing containers or recycling sacks was the method used in the Scottish trial, the Korean trial employed the same method. Indoor collection boxes and waste bags were provided to the daycare centers for free and collection containers were placed outside the daycare buildings. In the Scottish 
trial, all of the collected diaper waste was transported to the UK Knowaste recycling facility, which was already operational. However, since no such facility existed in Korea, the diaper waste was sent to the resource recovery facilities in the autonomous district and incinerated for heat recovery (Figure 1). The discarded diapers were processed as follows:

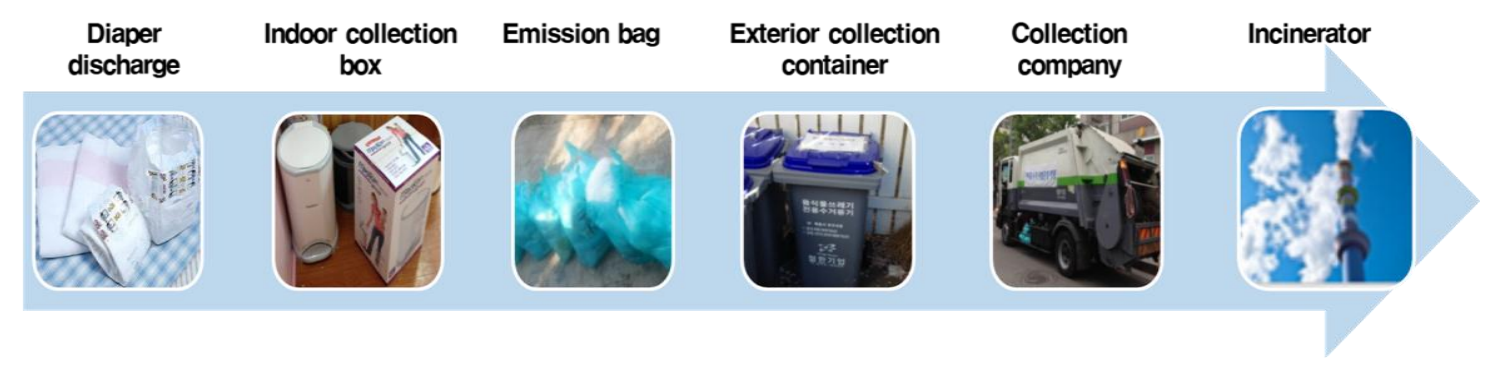

Figure 1. Diaper processing in the Korean collection trial.

Diapers were put inside the pre-distributed collection bags at the daycare centers and taken to their designated disposal locations at the assigned times; they were gathered up every other day by the collection companies [4]. Indoor collection boxes (16 L), waste bags (20 L) and stickers were provided to each of the participants. The sticker was designed to be visually attractive to promote the collection trial. The collection and transportation were done three times a week-six people were split into two regions and three vehicles were needed each day. In Korea, the municipal waste was usually separated two to three times a week. When we surveyed Korean mothers in advance, the favorite number of collections was two to three times a week and mothers were sensitive to odor. So, despite the high cost, we operated the collection trial with this frequency to increase policy acceptance.

The monitoring indicators for determining the success of the collection trial were classified into three categories-generation conditions, collection conditions and improvements (Table 5). The specific indicators included aspects of the generation of the diaper waste, treatment methods of the diaper waste, use of cloth diapers apart from disposable diapers, adequacy of the indoor collection box for the primary collection, adequacy of the exterior collection box for the secondary collection, functionality of the emission bag, cost of the collection, barriers to participating in the trial and motivation of the participants. While the Scottish trial conducted qualitative and quantitative research on the participants, the Korean trial monitored those engaged in the collection as well as the teachers at the daycare centers in Nowon-Gu. The monitoring was conducted by designated staff twice a week and the collection workers were monitored three times in total.

Table 5. Monitoring indicators of the Korean trial.

\begin{tabular}{cccc}
\hline Classification & Item & Daycare Center & Collection Company \\
\hline \multirow{2}{*}{ Generation } & Diaper generation & Daily average use & \\
& $\begin{array}{c}\text { Cloth diaper } \\
\text { Habstitute diaper use } \\
\text { Treatment }\end{array}$ & Handling method & \\
\hline \multirow{2}{*}{ Collection } & Indoor collection box & Location/volume/time & \\
& Outdoor collection box & Location/volume/time & Functionality of emission bag \\
\hline Transportation & Functionality & Functionality of emission bag & Vehicle/fuel efficiency \\
\hline
\end{tabular}

\subsection{Results}

\subsubsection{Generation}

On average, children were at the daycare centers from 9:00 a.m. to 4:00 or 7:00 p.m. As for children under age 1 , teachers changed their diapers 3-5 times per day (Table 6). In general, three were stool diapers and two just wet. Approximately $63 \%$ of the centers discarded the diapers still containing the 
stool, while 37\% flushed the stool down the toilet first. Three to 4 wipes were used for stool diapers and two wipes for wet diapers; the wipes were disposed of in the diapers.

Table 6. Daily diaper usage.

\begin{tabular}{|c|c|c|c|c|c|c|c|c|c|}
\hline Month & Ave. & $0-3$ & $4-6$ & 7-9 & 10-12 & $13-18$ & $19-24$ & $25-30$ & $31-36$ \\
\hline Diapers/day & 5.6 & 8.7 & 7.5 & 7.4 & 6.4 & 5.9 & 4.2 & 3.0 & 2.3 \\
\hline Ave./day & 5.6 & \multicolumn{5}{|c|}{7.5} & 5.05 & \multicolumn{2}{|r|}{2.65} \\
\hline
\end{tabular}

Through the first, second and third monitoring, it turned out that waste bags, which weighed 5 to $6 \mathrm{~kg}$, accounted for more than $63 \%$ of the total and the average weight of a emission bag was $4.76 \mathrm{~kg}(20 \mathrm{~L})$. The average number of diapers in a $20 \mathrm{~L}$ bag was 45 and their average weight was $103 \mathrm{~g}$. The expected waste generation was around 63 bags per day but the actual result was only around 16 bags per day. The reasons for the significant difference were: (1) the number of children who spent partial days at the daycare centers was relatively large and the number of children changed frequently due to moving; (2) small daycare centers had a low number of children who used diapers and the waste bags were not discarded until they were full; and (3) although diaper waste was constantly generated, there was confusion regarding the disposal box locations and days of collection.

\subsubsection{Collection}

At the collection stage, the arrangement of the indoor collection boxes, satisfaction with box capacity and efforts to reduce indoor odor were investigated. The indoor collection boxes were first filled and sealed before being put in the bags. The daycare-center staff were highly satisfied with the indoor collection boxes. Thirty-one percent of the daycare centers placed the bags outside the building, while $69 \%$ kept them inside. The daycare centers produced 9.3 bags per month on average; the weight of one bag was $4.76 \mathrm{~kg}$ on average; and about 45 used diapers were put in one $20 \mathrm{~L} \mathrm{bag}$. The weight of one diaper was approximately $103 \mathrm{~g}$ and the participants were generally satisfied with the material and usability of the bags. It took about 3 to $5 \mathrm{~min}$ to walk from the building to the exterior collection boxes, which were locked to prevent the introduction of other substances or domestic waste.

\subsubsection{Transportation}

The monitoring of service providers focused on the number of collection workers, vehicles, quantity of collection, average driving distance per day, hours of work and mileage. The personnel consisted of three drivers and three sanitary workers. It was estimated that it would take around two weeks to establish the collection routine. The bags did not tear and were airtight to reduce odor and the workers mentioned that they could barely smell any odor when collecting them. It took about 3-5 min on average to collect the bags at one point and one vehicle covered around $16-17 \mathrm{~km}$ per day. Those engaged in the collection trial said they felt a sense of accomplishment and being rewarded that diaper waste was being disposed of as they were supposed to be.

The actual costs were calculated by utilizing the data for the quantity of waste collected and the number of workers and vehicles used (Figure 2). The estimated quantity of diaper waste from the participating daycare centers was 2520 diapers per day. Allowing $100 \mathrm{~g}$ for each diaper, it was estimated that the 78 daycare centers generated $252 \mathrm{~kg}$ of diaper waste per day. However, the amount of diaper waste actually collected during the trial period of one and a half months totaled 3.12 tons, equivalent to $84 \mathrm{~kg}$ per day, with a collection rate of $33 \%$. Accordingly, the cost of collection and transportation in this trial was calculated as 1,671,786 won (\$1527) per ton. Based on a series of scenarios targeting Nowon-Gu, the costs were calculated with some changes in the quantity of collection and number of vehicles as follows. First, scenario 1 assumes that $100 \%$ of the diaper waste is collected from the 78 participating daycare centers and only one vehicle is used, which reduces the cost per ton to 518,078 won (\$473). Scenario 2 includes all 559 daycare centers in Nowon-Gu, a collection rate of $100 \%$ and two vehicles used for collection, which dramatically reduces the cost per ton to 193,069 won (\$176). 


\begin{tabular}{|c|c|c|c|c|}
\hline \multirow{2}{*}{\multicolumn{2}{|c|}{ Cost Items }} & \multirow[b]{2}{*}{ Trial Result } & Scenario 1 & Scenario 2 \\
\hline & & & $\begin{array}{l}78 \text { Participating } \\
\text { Daycare center }\end{array}$ & $\begin{array}{c}\text { Expansion to } 559 \\
\text { Daycare centers }\end{array}$ \\
\hline \multicolumn{2}{|c|}{ Participants } & 78 & 78 & 559 \\
\hline \multicolumn{2}{|c|}{ Collection Rate } & $33 \%$ & $100 \%$ & $100 \%$ \\
\hline \multicolumn{2}{|c|}{ Quantity } & 84kg (2.53t/month) & 252kg (7.56t/month) & 3.15t (94.5t/month) \\
\hline \multicolumn{2}{|c|}{ Daily Driving Distance } & $50 \mathrm{~km}$ & $50 \mathrm{~km}$ & $291 \mathrm{~km}$ \\
\hline \multirow{5}{*}{ Transportation } & Fuel efficiency & \multicolumn{3}{|c|}{5 ton Rubbish vehicle $(1.8 \mathrm{~km} / \mathrm{L})$} \\
\hline & No. of vehicles & 3 & 1 & 2 \\
\hline & Fuel consumption & 27.78 L/day & 27.78 L/day & 161.67 Lday \\
\hline & Fuel cost & $\begin{array}{c}1,416,667 \\
\text { won/month }\end{array}$ & $\begin{array}{c}1,416,667 \\
\text { won/month }\end{array}$ & $\begin{array}{c}8,245,000 \\
\text { won/month }\end{array}$ \\
\hline & Transportation cost & 560,007 won/t & 187,390 won/t & 87,249 won/t \\
\hline \multirow{5}{*}{ Collection } & Drivers & 3 people & 1 people & 2 people \\
\hline & Sweeper & 3 people & 1 people & 2 people \\
\hline & Working time & 1.5 hour & 4 hour & 8 hour \\
\hline & Labor cost & $\begin{array}{c}467,750 \\
\text { won/month }\end{array}$ & $\begin{array}{c}1,250,000 \\
\text { won/month }\end{array}$ & $\begin{array}{c}\text { 2,500,000 } \\
\text { won/month }\end{array}$ \\
\hline & Personnel expense & $1,111,779$ won/t & 330,688 won/t & 105,820 won/t \\
\hline \multicolumn{2}{|c|}{ Total cost } & $\begin{array}{c}1,671,786 \text { won/t } \\
(\$ 1,527)\end{array}$ & $\begin{array}{c}518,078 \text { won/t } \\
(\$ 473)\end{array}$ & $\begin{array}{c}193,069 \text { won/t } \\
(\$ 176)\end{array}$ \\
\hline
\end{tabular}

Figure 2. Transportation/collection costs of the Nowon-Gu trial [6].

\section{Discussion}

\subsection{Comparison with the Scottish Trial}

Table 7 below shows a comparison of the Scottish AHP and Korean disposable-diaper trials. Our research was not a simple one-on-one comparison between Scotland and Korea but as the Scottish trial preceded that in Korea, we aimed to mainly analyze Korea. We wanted to compare the structure of the diaper recycling project with the success factors in each society's environment, not the external factors. In order to introduce the policy of recycling of diapers, we wanted to benchmark the overseas cases that were widely carried out with a local government budget. The comparison with the Scottish case implied that the period of the trial should include summer to check the consequences of the bad smell that diaper waste gives off. This study was intended to find out different conditions in the cases of the two regions. In particular, the difference was clear from the point of view of the suppliers of the policy and the demanders of the policy. From a policy supplier's point of view, in Korea, no government funding was provided and the budget was provided by a diaper manufacturer. Scotland's waste recycling process has been operating for a long time with local government funding. Moreover, the trial should last at least three months, including a stabilization period in order to reach a certain standard. It is evident that the period of the trial is related to the budget. While the Scottish trial could last for six months thanks to the funding of local governments, the Korean trial ended more quickly due to the smaller amount of funding provided by the diaper manufacturers. 
Table 7. Comparison of the Scottish and Korean trials.

\begin{tabular}{ccc}
\hline Item & Scotland & Korea \\
\hline Background & $\begin{array}{c}\text { Zero Waste Scotland } \\
70 \% \text { recycling rate by 2025 }\end{array}$ & Nationwide recycling \\
\hline Budget & Scottish councils & Diaper manufacturers \\
\hline Target & Households & Daycare centers \\
\hline Period & 6 months & 6 weeks \\
\hline Frequency & Weekly & 3 times a week \\
\hline Provided items & Container, sacks & Indoor box, emission bag \\
\hline Recycling facility & Knowaste UK & \\
\hline Participation motivation & Env. conservation & \\
\hline
\end{tabular}

From a policy demander's point of view, Scotland was satisfied with its once a week collection. Korea ran a collection of diapers three times a week, as participants were very against keeping them indoors for more than two days. If a diaper recycling policy was introduced, it would have revealed personal discomfort rather than participation in the collection trial. Therefore, the difference is clear from the point of view of the policy demander. If diaper recycling is introduced in Korea, it is considered significant to suggest a more acceptable collection method. The cost of collection was higher in the Korean trial, where the collection rate was only $33 \%$, which might also be attributable to the fact that the vehicles for collection were used once a week in Scotland, while three times a week in Korea. To promote the recycling of diaper waste as a policy in Korea, a collection trial needs to be conducted for more than three months across a wider range of areas with the financial support of the Ministry of Environment. However, since the cost burden was high in this trial targeting Nowon-Gu, the frequency of collection should be reduced to twice a week and the targets should be expanded to other daycare centers in Nowon-Gu, or even all daycare centers in Seoul, to determine economic feasibility.

\subsection{Optimization of Collection Cost}

The high cost per ton of actual trial in this study was due to the lack of conditions currently present in the collection company that would specialize in diaper collection and the limited number of participating daycare centers and small quantity of diaper waste collected. So, it was hoped to improve the results of this study to optimize collection and transportation costs. Therefore, optimizing the collection/transportation costs by addressing the factors that incur them will contribute to making the recycling of diaper waste more economically feasible. The cost factors consist of collection and transportation factors. As you can see in Figure 3, a significant cost influencing factor was the quantity of collection and the number of vehicles, which is associated with frequency of collection. The most important variable was the quantity of collection and this would result in the number of vehicles and the number of working people deployed. Fuel efficiency and collection frequency were considered as the next major variables. The daily distance was defined as the total length of the area, so we could optimize the route through which the collection vehicles were travelling.

Based on the assumption that a collection trial will be expanded to include all of the daycare centers in Seoul, the costs of collection/transportation are calculated as follows. The variables include the quantity of diaper waste, frequency of collections and mileage of vehicles. Based on the number of children in Seoul as provided by the National Statistics Office, the quantity of diaper waste generated can be estimated at 53.28 tons per day, or 1598 tons per month. In Nowon-Gu and Gangseo-Gu, which have the largest numbers of children in Seoul, approximately 100 tons of diaper waste can be expected every month. First, the total quantity of diaper waste generated by the daycare centers in Seoul is calculated. Second, the rate of collection is increased from $33 \%$ to $100 \%$. Third, for two scenarios, we set the frequency of collections as twice and three times a week. And fourth, we set two mileage rates for the vehicles as $1.8 \mathrm{~km} / \mathrm{L}$ and $3.6 \mathrm{~km} / \mathrm{L}$. Using this research result, we calculated the cost by setting the variables of collection quantity, collection frequency and fuel efficiency and 
changing the options when applying the results of an extended application throughout Seoul. It was not perfect because it did not reflect all variables. It is more correct to say that the scenarios are options by collection method. The various options were intended to see what was appropriate in Korea. As a result, the scenario for collecting diaper waste three times a week estimates the cost of collection/transportation between 112,396 won $(\$ 103) /$ ton and 256,655 won $(\$ 234) /$ ton, while that for collecting twice a week puts it between 102,708 won $(\$ 94) /$ ton and 197,943 won $(\$ 181) /$ ton. Realistically, it is difficult to collect more than $70-80 \%$ of waste such as diapers generated by a certain group of consumers, so it will be more economically feasible to operate highly efficient collection vehicles twice a week (Figure 4).

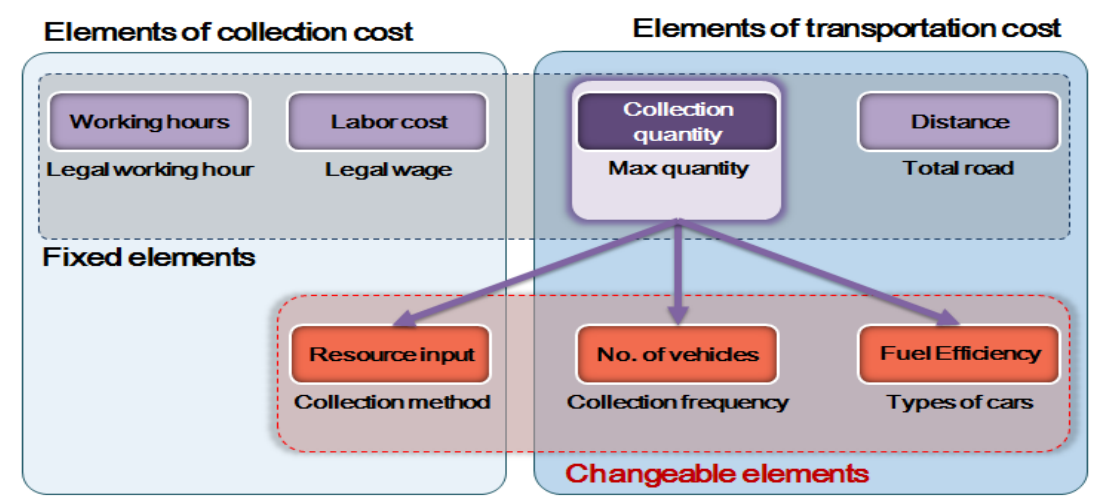

Figure 3. Transportation/collection costs of the Nowon-Gu trial [6].

\begin{tabular}{|c|c|c|c|c|c|c|c|}
\hline \multicolumn{3}{|c|}{ Cost Items } & Scenario 1 & Scenario 2 & Scenario 3 & Scenario 4 & Scenario 5 \\
\hline \multicolumn{3}{|c|}{ Collection Rate } & $33 \%$ & $50 \%$ & $75 \%$ & $90 \%$ & $100 \%$ \\
\hline \multicolumn{3}{|c|}{ Quantity } & $527.49 \mathrm{t} / \mathrm{mon}$ & $799.23 \mathrm{t} / \mathrm{mon}$ & $1,198.85 \mathrm{t} / \mathrm{mon}$ & $1,438.62 \mathrm{t} / \mathrm{mon}$ & $1,598.46 \mathrm{t} / \mathrm{mon}$ \\
\hline \multicolumn{3}{|c|}{ Daily Quantity } & $21.98 \mathrm{t}$ & $33.30 \mathrm{t}$ & $49.95 t$ & $59.94 t$ & $66.60 \mathrm{t}$ \\
\hline \multicolumn{3}{|c|}{ No. of vehicles } & 6 & 10 & 15 & 18 & 20 \\
\hline \multicolumn{3}{|c|}{ Sweeper } & 11 & 17 & 25 & 30 & 33 \\
\hline \multicolumn{3}{|c|}{$\begin{array}{l}\text { Personnel expense } \\
\text { (won/month) }\end{array}$} & $42,473,583$ & $66,602,626$ & $99,903,940$ & $119,884,728$ & $133,205,253$ \\
\hline \multirow{4}{*}{$\begin{array}{l}2 \text { times } \\
\text { /week }\end{array}$} & \multicolumn{2}{|c|}{$\begin{array}{l}\text { Daily Driving } \\
\text { Distance }\end{array}$} & \multicolumn{5}{|c|}{$2,733 \mathrm{~km} /$ day } \\
\hline & \multicolumn{2}{|c|}{ Fuel cost (month) } & \multicolumn{5}{|c|}{$\begin{array}{l}\text { Fuel efficiency } 1.8 \mathrm{~km} / \mathrm{L}: \quad 61,939,931 \text { won } / \text { month } \\
\text { Fuel efficiency } 3.6 \mathrm{~km} / \mathrm{L}: 30,969,965 \text { won } / \text { month }\end{array}$} \\
\hline & $\begin{array}{c}\text { Collec } \\
\text { tion }\end{array}$ & $\begin{array}{c}\text { Fuel efficiency } \\
1.8 \mathrm{~km}\end{array}$ & $\begin{array}{l}197,943 \text { won } \\
\quad(\$ 181)\end{array}$ & $\begin{array}{l}160,833 \text { won } \\
(\$ 147)\end{array}$ & $\begin{array}{l}135,000 \text { won } \\
(\$ 123)\end{array}$ & $\begin{array}{c}126,389 \text { won } \\
(\$ 115)\end{array}$ & $\begin{array}{l}122,083 \text { won } \\
(\$ 111)\end{array}$ \\
\hline & $\begin{array}{l}\text { cost } \\
(\text { won } / t)\end{array}$ & $\begin{array}{c}\text { Fuel efficiency } \\
3.6 \mathrm{~mm}\end{array}$ & $\begin{array}{l}139,231 \text { won } \\
(\$ 127)\end{array}$ & $\begin{array}{l}\text { 122,083 won } \\
\text { (\$111) }\end{array}$ & $\begin{array}{c}109,166 \text { won } \\
(\$ 99)\end{array}$ & $\begin{array}{l}\text { 104,861 won } \\
\text { (\$96) }\end{array}$ & $\begin{array}{l}\text { 102,708 won } \\
\text { (\$94) }\end{array}$ \\
\hline \multirow{4}{*}{$\begin{array}{l}3 \text { times } \\
\text { /week }\end{array}$} & \multicolumn{2}{|c|}{$\begin{array}{l}\text { Daily Driving } \\
\text { Distance }\end{array}$} & \multicolumn{5}{|c|}{ 4,099 km/day } \\
\hline & \multicolumn{2}{|c|}{ Fuel cost (month) } & \multicolumn{5}{|c|}{$\begin{array}{l}\text { Fuel efficiency } 1.8 \mathrm{~km} / \mathrm{L}: \quad 61,939,931 \text { won } / \text { month } \\
\text { Fuel efficiency } 3.6 \mathrm{~km} / \mathrm{L}: 30,969,965 \text { won } / \text { month }\end{array}$} \\
\hline & \multirow{2}{*}{$\begin{array}{l}\text { Collec } \\
\text { tion } \\
\text { cost } \\
\text { (won } / t)\end{array}$} & $\begin{array}{c}\text { Fuel efficiency } \\
1.8 \mathrm{~km}\end{array}$ & $\begin{array}{l}256,655 \text { won } \\
(\$ 234)\end{array}$ & $\begin{array}{l}199,582 \text { won } \\
(\$ 182)\end{array}$ & $\begin{array}{l}160,833 \text { won } \\
(\$ 147)\end{array}$ & $\begin{array}{l}147,916 \text { won } \\
(\$ 135)\end{array}$ & $\begin{array}{l}141,458 \text { won } \\
(\$ 129)\end{array}$ \\
\hline & & $\begin{array}{c}\text { Fuel efficiency } \\
3.6 \mathrm{~km}\end{array}$ & $\begin{array}{l}168,587 \text { won } \\
(\$ 154)\end{array}$ & $\begin{array}{l}141,458 \text { won } \\
(\$ 129)\end{array}$ & $\begin{array}{l}122,083 \text { won } \\
\text { (\$111) }\end{array}$ & $\begin{array}{l}115,625 \text { won } \\
(\$ 105)\end{array}$ & $\begin{array}{l}\text { 112,396 won } \\
\text { (\$ 103) }\end{array}$ \\
\hline
\end{tabular}

Figure 4. Optimization of the transportation/collection cost. 


\section{Conclusions}

Currently, disposable diapers are subject to waste charges and thus sent to incineration or landfill, although they can be recycled. In addition, since disposable diapers contain a considerable amount of valuable and recyclable resources, the collection/transportation system and recycling process should be optimized to introduce the policy of diaper recycling. To that end, practical technology and collection efficiency should be secured. More related research work is required due to the lack of reliable positive studies. The economic feasibility of diaper recycling was analyzed by the Korea Environment Corporation in 2006 and by lawmaker Eun Su-Mi's office in 2012. The costs of collection and transportation accounted for $15-52 \%$ of the total and their studies provided hope for attaining economic feasibility. In this regard, this study conducted a diaper waste collection trial to find the difficulties with collection and also identify the relevant cost factors for suggesting optimal methods. First, the results of the Scottish AHP collection trial in 2012 were examined. In it, the most important factors were the opt-in rate, which refers to the rate of participation and the service of providing containers and recycling sacks to the households, since these factors resulted in the highest rates of collection. Moreover, engagement programs, including informative brochures, contributed to promoting the service to the public. A number of the participants said that they believed the recycling of diaper waste would contribute to environmental protection and the creation of better products. As a result of providing the service for six months, the most optimized area, with weekly collections and a collection rate of $75-86 \%$, showed an average collection cost of $£ 1100 /$ ton.

Applying the method showing the highest efficiency in the Scottish trial, containers and $30 \mathrm{~L}$ sacks, the Korean trial targeted daycare centers for the quantity of diaper waste they produce. The residential areas in Korea are inconvenient for large vehicles to move in and many residential areas do not contain large apartment complexes. Therefore, daycare centers, especially ones that could be easily accessed by collection vehicles, were selected as the targets considering both their large quantity of waste and transportation convenience. Since the Korean collection trial could not last long due to the limited budget, publicity/education on the necessity of recycling was barely provided for the participants; thus, a lot of mistakes were made during the process of collection. Furthermore, there was a difference in quantity between the expected and actual amounts collected due to an unexpected number of children who spent shorter times at the daycare centers and participants who were confused about the location for diaper disposal and days of collection. Therefore, to expand the target groups and increase the scale of the collection in the future, education and publicity activities should be arranged in advance. At the stage of collection, participants primarily utilized the indoor collection boxes and then put the airtight boxes into waste bags before placing them outside the buildings. The level of satisfaction with the use of the indoor collection boxes was high and the daycare centers also made efforts to reduce the bad odor on their own. The trial lasted for six weeks, with a collection frequency of three times a week and the collection rate was less than $50 \%$. Since the trial ended only two weeks after the participants had become competent with the routine, the results were not cost effective. The reasons why the collection cost per ton was high in the Korean case are as follows: (1) it took some time for the participants to reach a full understanding of how to use the service and follow the directions closely but the period of the collection trial was rather short; (2) the collection companies were not capable of dealing with diaper waste only, meaning a lack of efficiency in the collection and transportation system and (3) the limited number of participants, leading to a small quantity of collected waste, could not achieve economies of scale.

Under current Korean waste regulations, diapers cannot be collected with municipal waste or food waste. If cost-efficient diaper collection is secured through this study, it will be possible to treat it like other types of municipal waste through the amendment of regulations. To promote the recycling of diaper waste as a policy in Korea, a trial needs to be carried out in a wider area by obtaining funding from the Ministry of Environment. It is still meaningful that this trial successfully identified the collection and transportation factors. However, the collection frequency of three times a week and requirement of many worker hours compared to the small quantity of waste resulted in an excessive 
cost of collection. Therefore, the new trial should be conducted twice a week targeting the daycare centers in the rest of Nowon-Gu or all of Seoul to analyze the economic feasibility of the project. In fact, this study can suggest the most optimized model for collection efficiency after evaluating various scenarios regarding collection cost for the daycare centers of Nowon-Gu. Using this result, the cost by setting the variables of collection quantity, collection frequency and fuel efficiency was calculated and the options when applying the results of an extended application throughout Seoul was identified. It is more correct to say that the scenarios in this study are optional application by collection method. The various options were intended to see what was appropriate in Korea, not to compare Scottish and Korean cases on the same views. In addition, mid to long-term plans should be laid to expand the collection trial to apartment housing areas and other provinces. To increase participation in the trial, the role of citizens in environmental protection should be emphasized and public awareness should be enhanced with regard to the need to reduce the costs of waste treatment and the consumption of energy and resources. Furthermore, participant behavior regarding diaper-waste discharge should be monitored to validate the collection model, all of which will contribute to establishing a more socially acceptable diaper-recycling system.

Author Contributions: Kyung-Shin Kim initiated this research and Kyoung Jin Kim analyzed data and provided comments. Both authors were engaged in the final manuscript preparation and agreed to the publication of this paper.

Conflicts of Interest: The author declares no conflict of interest.

\section{References}

1. Kim, K.S.; Cho, H.S. Pilot trial on separation conditions for diaper recycling. Waste Manag. 2017, 67, 11-19. [CrossRef] [PubMed]

2. Choi, K.H. Properties of fluff pulp and hand sheet recycled from paper diaper. J. Korea Tech. Assoc. Pulp. Pap. Ind. 2015, 47, 93-101. [CrossRef]

3. Kim, K.S. Research on collection method of used diaper based on foreign collection method and perception survey. J. Ind. Resour. Recycl. 2017, 26, 29-38.

4. Kim, K.J.; Kim, K.S. The gap between attitudes toward diaper recycling and the actual behavior of daycare teachers and parents. J. Environ. Policy 2015, 23, 77-96. [CrossRef]

5. Kim, K.S.; Yun, S.J. Diaper recycling policy design options with a focus on influential factors of recycling behavior: Based on a survey on citizens' awareness in Seoul. J. Environ. Policy 2014, 22, 101-130. [CrossRef]

6. Kim, K.S. Policy options for diaper recycling to foster effective citizens' participation based on collection pilot test of soiled diaper in Nowon-gu. J. Ind. Resour. Recycl. 2015, 24, 16-26. [CrossRef]

7. Mirabella, N.; Castellani, V.; Sala, S. Life cycle assessment of bio-based products: A disposable diaper case study. Int. J. Life Cycle Assess. 2013, 18, 1036-1047. [CrossRef]

8. Espinosa-Valdemara, R.M.; Sotelo-Navarroa, P.X.; Quecholac-Piña, X.; García-Rivera, M.A.; Beltrán-Villavicencio, M.; Ojeda-Benítez, S.; Vázquez-Morillas, A. Biological recycling of used baby diapers in a small-scale composting system. Resour. Conserv. Recycl. 2014, 87, 153-157. [CrossRef]

9. Torrijos, M.; Sousbie, P.; Rouez, M.; Lemunier, M.; Lessard, Y.; Galtier, L.; Simao, A.; Steyer, J.P. Treatment of the biodegradable fraction of used disposable diapers by co-digestion with waste activated sludge. Waste Manag. 2014, 34, 669-675. [CrossRef] [PubMed]

10. Colon, J.; Ruggieri, L.; Sanchez, A.; Gonzalez, A.; Puig, I. Possibilities of composting disposable diapers with municipal solid waste. Waste Manag. Res. 2011, 29, 249-259. [CrossRef] [PubMed]

11. Colon, J.; Mestre, M.; Puig, I.; Sanchez, A. Performance of compostable baby used diapers in the composting process with the organic fraction of municipal solid waste. Waste Manag. 2013, 33, 1097-1103. [CrossRef] [PubMed]

12. Deloitte. Absorbent Hygiene Products Comparative Life Cycle Assessment. 2011. Available online: http://www.practicalgreenparent.com/wp-content/uploads/2014/08/Deloitte-dcarbon8_KnowasteLCA_Exec_Summary.pdf (accessed on 6 October 2017).

13. Cook, B.D.; Bloom, P.R.; Halbach, T.R. Fate of a polyacrylate polymer during composting of simulated municipal solid waste. J. Environ. Qual. 1997, 26, 618-625. [CrossRef] 
14. Manfredi, S.; Tonini, D.; Christensen, T.H. Contribution of individual waste fractions to the environmental impacts from landfilling of municipal solid waste. Waste Manag. 2010, 30, 433-440. [CrossRef] [PubMed]

15. Slater, R.A.; Frederickson, J. Composting municipal waste in UK: Some lessons from Europe. Resour. Conserv. Recycl. 2001, 32, 359-374. [CrossRef]

16. Stegmann, R.; Lotter, S.; King, L. Fate of an absorbent gelling material for hygiene paper products in landfill and composting. Waste Manag. Res. 1993, 11, 155-170. [CrossRef]

17. Mok, J.H. A Study on the Recycling of Disposable Diaper; Kookmin University: Seoul, Korea, 2006.

18. Weisbrod, A.V.; Van Hoof, G. LCA-measured environmental improvements in Pampers diapers. Int. J. Life Cycle Assess. 2012, 17, 145-153. [CrossRef]

19. Nicki Souter Associates. Evaluation of the Absorbent Hygiene Products Collection Trials in Scotland; Nicki Souter Associates: Scotland, UK, 2013.

(C) 2018 by the authors. Licensee MDPI, Basel, Switzerland. This article is an open access article distributed under the terms and conditions of the Creative Commons Attribution (CC BY) license (http://creativecommons.org/licenses/by/4.0/). 